\title{
SURFACE MORPHOLOGY AND DYNAMICS: USING AB-INITIO TOTAL ENERGIES TO MAKE THE MOST OF STM DATA
}

\author{
PETER J. FEIBELMAN \\ Sandia National Laboratories \\ Albuquerque, NM 87185-1413
}

\begin{abstract}
Ab-initio total energies test typically model-dependent results of interpreting STM morphologies, and can explain what mechanisms underlie morphology change with time. Ab-initio step- and kink-formation energies for $\mathrm{Pb}(111)$ and $\mathrm{Pt}(111)$, e.g., show that the experimental results must be revised. Calculations of $\mathrm{S}$-decorated $\mathrm{Cu}$ adclusters point to ad- $\mathrm{Cu}_{3} \mathrm{~S}_{3}$ as an agent of $\mathrm{S}$-enhanced $\mathrm{Cu}$ transport between islands on $\mathrm{Cu}(111)$, in a novel "skyhook effect."
\end{abstract}

\section{INTRODUCTION}

Scanning Tunneling Microscopy (STM) has revolutionized surface science by providing atomic-resolution images of a broad range of surfaces. Still, STM data is often as challenging to interpret as any from the host of techniques used to understand surface structure and dynamics. I offer examples here that reveal the power of modern first-principles total-energy calculations to help derive maximum value from STM observations of surface morphology and its time-evolution, whether in the form of reliable, quantitative surface energetic information or a plausible mechanistic scenario.

In the first instance, ${ }^{1,2}$ I consider step- and kink-formation energies, fundamental parameters in the quasi-continuum description of surface morphology, and key to predicting how surfaces evolve in time. Because step wandering is governed by kink-formation energetics and the orientation-dependence of step-formation cost determines equilibrium island shapes, "experimental" values of these energies are generally obtained as best-fit parameters in comparisons between continuum surface models and STM data. ${ }^{3-7}$

As in the case of any fit, it is important to question the systematic reliability of the results. In this case we are fortunate that surface geometry imposes testable relationships between kink- and step-formation energies. ${ }^{1,2}$ Supported by evidence from large-scale, $a b$-initio, total-energy calculations, ${ }^{1,2}$ these tests necessitate revisions of the kink energies published for both $\mathrm{Pt}(111)^{3}$ and $\mathrm{Pb}(111)^{6}$ 


\section{DISCLAIMER}

This report was prepared as an account of work sponsored by an agency of the United States Government. Neither the United States Government nor any agency thereof, nor any of their employees, make any warranty, express or implied, or assumes any legal liability or responsibility for the accuracy, completeness, or usefulness of any information, apparatus, product, or process disclosed, or represents that its use would not infringe privately owned rights. Reference herein to any specific commercial product, process, or service by trade name, trademark, manufacturer, or otherwise does not necessarily constitute or imply its endorsement, recommendation, or favoring by the United States Government or any agency thereof. The views and opinions of authors expressed herein do not necessarily state or reflect those of the United States Government or any agency thereof. 


\section{DISCLAIMER}

Portions of this document may be illegible in electronic image products. Images are produced from the best available original document. 
The other example discussed in this review bears on how surface impurities, whether adventitious or deposited purposely, affect growth morphology. Surface scientists have devoted a decade's work to "surfactant-directed" self-assembly of ultra-thin films, with the idea that judicious addition of impurities might make it possible to build desired nanostructures more easily -- or in some cases, at all. ${ }^{8}$ However, recent difficulties in interpreting experimental data have focused concern on the equally important effects of impurities not deposited purposely. ${ }^{9}$. The evidence is that they need to be considered even when the impurity concentration is low. The reason is that impurities are attracted to sites where valence is relatively unsaturated, namely, defects. If surface defects, such as steps or vacancies, control the development of surface morphology, then a small impurity concentration may saturate the small number of defects and thus have a large effect.

In the case discussed here, time-resolved STM shows that $\mathrm{S}$ adatoms cause monolayer-high $\mathrm{Cu}$ islands on thick $\mathrm{Cu}(111)$ films to ripen $\sim 3-4$ orders of magnitude faster than when impurities are absent. ${ }^{10}$ To understand how this can be, I ask what $\mathrm{Cu}_{n} \mathrm{~S}_{m}$ clusters form more readily on $\mathrm{Cu}(111)$ than a $\mathrm{Cu}$ adatom, and diffuse easily. ${ }^{11} \mathrm{~A}$ systematic ab-initio search implies that the smallest such cluster is ad- $\mathrm{Cu}_{3} \mathrm{~S}_{3}$. Its formation energy is $\sim 0.5 \mathrm{eV}$ lower than a Cu adatom's, and, corresponding to tight internal bonding, its diffusion barrier is $\leq 0.35 \mathrm{eV}$ : This means that $\mathrm{S}$ can speed island ripening on $\mathrm{Cu}(111)$ by acting as a "skyhook," 12 weakening the bonds of a $\mathrm{Cu}$ adatom cluster to the substrate and promoting its transport.

\section{STEP-AND KINK-FORMATION ENERGIES ON $f c c(111)$ METAL SURFACES}

Several methods have been used to extract formation energies of steps and kinks on fcc(111) surfaces from the statistics of step- and island morphologies observed in STM. To understand them one must first appreciate that a hexagonal substrate supports two types of unkinked steps, (100)-microfacets, called A-type steps, and (111)-microfacets, known as "B-type" steps (See Fig. 1). The two types, in principle, have different formation energies, reflecting their distinct geometries. The energies needed to form kinks in each may also be different for the same reason.

\section{Experimental step-formation energy ratios}

Michely and Comsa (MC) were the first to measure a ratio of A- and B-step formation energies. They did so, on $\mathrm{Pt}(111),{ }^{13}$ starting from the observation that aspect ratios of vacancy and adatom islands of various sizes are all the same after the sample is raised to $>700 \mathrm{~K}$ and then cooled rapidly. Since this implies that the ratio of A-to B-step lengths $\mathrm{L}_{\mathrm{A}} / \mathrm{L}_{\mathrm{B}}$ is thermodynamically determined, they used the thermodynamic formula for the step formation energy ratio,

$$
\mathrm{E}_{\mathrm{A}} / \mathrm{E}_{\mathrm{B}}=\left(2+\mathrm{L}_{\mathrm{A}} / \mathrm{L}_{\mathrm{B}}\right) /\left(2 \mathrm{~L}_{\mathrm{A}} / \mathrm{L}_{\mathrm{B}}+1\right)
$$


which applies when $L_{A}$ and $L_{B}$ are measurably greater than zero. For $P t(111), M C$ found that $L_{A} / L_{B}=0.66$, corresponding to $E_{A} / E_{B}=1.15$. Thus, to form an A-type step requires $15 \%$ more energy, per unit length, than to form a B-type step. Application of essentially the same strategy subsequently produced values of $E_{A} / E_{B}=1.011 \pm 0.0007$, $0.996 \pm 0.0025$ and 1.11 for step formation on $\mathrm{Cu}(111),{ }^{14} \mathrm{Ag}(111)^{14}$ and $\mathrm{Pb}(111){ }^{8}$

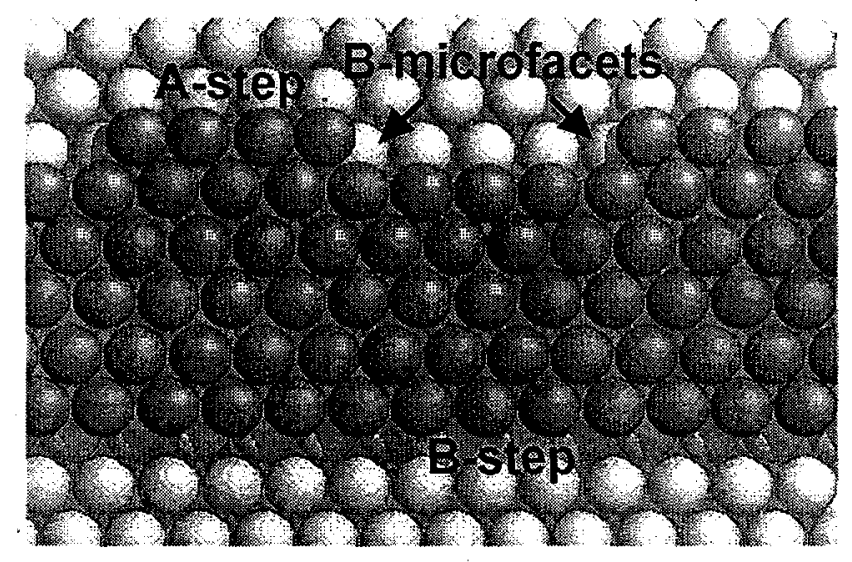

Fig. 1. A kinked, stripe island, 6 atom-rows wide, on an fec(111) surface. The "A-type" edges of the stripe are (100)- and (111)-microfaces. The kinks in the A-type edge are B-type microfacets one atomic spacing long.

\section{Experimental Absolute Step-formation Energies}

Measuring an absolute step-formation energy demands observing a quantity with dimensions of energy. In a method recently invented by Icking-Konert, Giesen and Ibach (IGI), ${ }^{4}$ the sample temperature, $\mathrm{T}$, is the needed energy reference. In an Ising model framework, SGI formally compute the T-derivative of the ratio of the free energies of a " $100 \%$ kinked step," e.g., a $<11 \overline{2}>$-oriented step on a (111) surface, and a straight, $<01 \overline{1}>$-oriented step. To within known constants, they show that at low $\mathrm{T}$ this derivative equals the inverse of the $<01 \overline{1}>$ step's formation energy.

The required free-energy ratio can be measured, according to thermodynamics, by comparing the distances from an equilibrium island's center to its sides and corners. Thus IGI determine step formation energies by observing the change with $T$ of an appropriate distance ratio. This group's most recent results are by Giesen, Steiner and Ibach (GSI) ${ }_{2}^{14}$ who report average straight-step formation energies of $0.27 \pm 0.03$ and $0.25 \pm 0.03$ eV/atom on $\mathrm{Cu}$ and $\mathrm{Ag}(111)$.

An alternate way to determine absolute step formation energies, proposed by Schlößer, et al. is to measure island shape fluctuations as a function of temperature. ${ }^{5}$ From the results one extracts the step-formation energy as the line tension of the island perimeter. The method is formulated for circular rather than hexagonal islands and is 
based on a continuum model. Nonetheless, the result for steps on $\mathrm{Cu}(111)$, a formation energy of $0.22 \mathrm{eV} / \mathrm{atom}$, is within $25 \%$ of GSI's value. ${ }^{14}$

Yet a third way to extract step formation energies from data is used by Arenhold, et al., in which the energy reference is an average surface energy. ${ }^{6}$ Since the surface energies of solids are rather poorly known, this accuracy of this approach is inherently limited. Notwithstanding, Arenhold, et al. use the fact that the ratio of the average radius of a (111) facet on a crystallite to the crystallite radius equals the ratio of the average step and surface energies. Based on extrapolated measurements on $\mathrm{Pb}$ liquid droplets, which yield a $\mathrm{Pb}$ surface energy $\sim 38 \mathrm{meV} / \AA^{2}$, Arenhold, et al. determine an average step formation energy on $\mathrm{Pb}(111)$ of $\sim 87 \mathrm{meV} /$ atom at $440 \mathrm{~K}^{6}$

\section{Relation between step- and kink-formation energies}

As Swartzentruber, et al. ${ }^{15}$ first pointed out and exploited, kink- and step-formation energies are related because creating a kink amounts to creating additional step length. On a (111)-surface, where A- and B-steps intersect at $120^{\circ}$ angles (see Fig. 1), creating a kink in an A-type step: a) adds a B-type microfacet one inter-atomic spacing long, b) eliminates one-half that length of the original A-type step, and c) adds two $120^{\circ}$ corners, one convex, the other concave. To form such a kink thus requires energy,

$$
E_{K}(A ; 1)=E_{S}(B)-E_{S}(A) / 2+E_{C}(A)
$$

where $E_{S}(A)$ and $E_{S}(B)$ are the formation energies per atom of $A$ - and B-type steps and the last term is, by definition, a "corner-formation" energy for an A-step. ${ }^{15}$ Extending the new B-step from one to $n_{k}$ inter-atom spacings, the formation-energy increases to

$$
E_{K}\left(A ; n_{k}\right)=n_{k}\left[E_{S}(B)-E_{S}(A) / 2\right]+E_{C}\left(A ; n_{k}\right)
$$

where $E_{C}\left(A ; n_{k}\right)$ approaches a constant as $n_{k}$ becomes sufficiently large that the convex and concave corners no longer interact. The same applies for a B-steps yielding formation-energy,

$$
E_{K}\left(B ; n_{k}\right)=n_{k}\left[E_{S}(A)-E_{S}(B) / 2\right]+E_{C}\left(B ; n_{k}\right)
$$

For asymptotically-large $n_{k}$, Eqs. 3 and 4 combine to allow evaluation of the stepformation energy difference. The reason is that if the concave and convex corners that delimit a kink are too far ăpart to interact, then geometry dictates that $E_{C}\left(A ; n_{k}\right)$ and $E_{C}\left(B ; n_{k}\right)$ must be equal, i.e.,

$$
E_{C}\left(A ; n_{k}\right)=E_{C}\left(B ; n_{k}\right) \equiv E_{C}, n_{k} \rightarrow \infty
$$

Subtracting Eq. 4 from Eq. 3 in this limit, one finds, 


$$
E_{K}\left(A ; n_{k}\right)-E_{K}\left(B ; n_{k}\right)=3 n_{k}\left[E_{S}(B)-E_{S}(A)\right] / 2, n_{k} \rightarrow \infty,
$$

which yields the step-formation energy difference in terms of calculated kink-formation energies, $E_{K}\left(A ; n_{k}\right)$ and $E_{B}\left(B ; n_{k}\right)$. From the numerical standpoint, an important question is whether one is already in the asymptotic region when $n_{k}$ is small enough that calculations of kinked edges are practical. In fact, reasonable results are obtained even assuming that Eq. 5 is valid for $n_{k}=1$.

\section{Experimental kink energies vs. Eq. 6}

The bending of a surface step, whether at the rounded corner of an island or as it wanders diffusively, is governed in continuum models by its "stiffness" and in microscopic models by the kink-formation energy. ${ }^{7}$ Thus kink energies are measured by observing island shapes or step-wandering and parameterizing the results via a lattice gas model of the stiffness.

Though the parameterization in principle includes both an energy per unit kink length and a comer energy, the latter has typically been assumed to be small enough that it can be neglected. What has only recently been recognized ${ }^{1,2}$ is that if the corner energies are negligible, then Eq. 5 is automatically true, and Eq. 6 follows. This being the case Eq. 6 should be used to check the consistency of the results derived from experiment.

Applying this test immediately points to a problem for Pt(111), namely that Giesen, et al.'s measured ratio of 1 for kink-formation energies on A- and B-type steps ${ }^{3}$ is inconsistent with Michely and Comsa's ratio of 1.15 for the step-formation energies. ${ }^{13}$. According to Eq. 6, equality of the kink-formation energies on A- and B-type steps implies equal step-formation energies.

This argument is reinforced by Density Functional Theory (DFT) calculations in the Local Density Approximation (LDA) ${ }^{16}$ (see Ref. 1 for a detailed exposition of the method), according to which,

$$
E_{S}(A)+E_{S}(B)=0.75 \text { eV/atom }
$$

and the difference of kink-formation energies is

$$
E_{K}(B ; 1)-E_{K}(A ; 1)=0.07 e V .
$$

Combining Eqs. 6 and 8, one obtains

$$
E_{S}(A)-E_{S}(B)=0.05 \mathrm{eV} / \text { atom. }
$$


Solving Eqs. 7 and 9 then yields $E_{S}(A)=0.40 \mathrm{eV} /$ atom, $E_{S}(B)=0.35 \mathrm{eV} /$ atom, and $E_{S}(A) / E_{S}(B)=1.14$. The first two of these results agree reasonably well with Boisvert, et al.'s vicinal surface calculations. ${ }^{17}$ The last agrees closely with Michely and Comsa's ratio, 1.15 .

Thus, the relationship between step and kink energies based on Eq. 5 appears to hold, theoretically, and revisiting the interpretation of the experimental results is necessary. The authors of Ref. 3 suggest that difficulties in determining the crystal orientation of observed steps may be the source of the problem. ${ }^{18}$

Reconsideration of Arenhold, et al.'s kink energies for $\mathrm{Pb}(111)$ also reveals a problem, but its source is quite different. ${ }^{6}$ In Ref. 6 , kink-formation energies $E_{K}\left(A ; n_{k}\right)=n_{k} \times 61 \mathrm{meV}$ and $E_{K}\left(B ; n_{k}\right)=n_{k} \times 87 m e V$ are extracted from measurements of island corner rounding, once again under the assumption that the comer energies, $E_{C}=0$. Substituting these results into Eqs. 3 and 4 along with the measured A- and B-step formation energies, $90.7 \mathrm{meV} /$ atom and $81.9 \mathrm{meV} /$ atom, immediately indicates inconsistencies, namely the corner energies for A- and B-type steps cannot be independent of $n_{k}$, they cannot be equal and certainly are not zero. Assuming that the corner energies vanish thus leads to a contradiction.

In this case, the trouble is that the formula used in Ref. 6 to obtain kink energies from step-stiffness measurements was one derived for steps on a square lattice, which turns out not to be a good approximation to Akutsu and Akutsu's (AA's) result for the hexagonal case. ${ }^{19}$

Reanalyzing the experimental data with $\mathrm{AA}$ 's formula, one obtains revised experimental kink-formation energies, namely, $\mathrm{E}_{\mathrm{K}}(\mathrm{A})=42 \mathrm{meV}$ and $\mathrm{E}_{\mathrm{K}}(\mathrm{B})=69 \mathrm{meV}$. As in the case of step-formation energies, these results are known only as well as the $\mathrm{Pb}(111)$ surface energy, to which they are scaled. If the surface energy were 35 instead of $38 \mathrm{meV}$, the $a b$ initio result obtained using the Generalized Gradient Approximation (GGA), ${ }^{20}$ the formation of kinks on A- and B-steps would instead be found to cost 39 and $64 \mathrm{meV}$. These values are in good agreement with the GGA kink formation energies, 41 and 60 $\mathrm{meV}$.

\section{Lessons learned}

Important lessons can be drawn from this work:

a) Because steps and kinks are geometrically related, it is a mistake to view stepand kink-formation energies in isolation. The two types of formation energy are related, and their inter-comparison can signal error in the analysis of experimental information.

b) Care is essential in assuming that formulae valid for one surface symmetry extend to another.

c) GGA provides a reasonably accurate description of the defect energetics of $\mathrm{Pb}$. This result, together with a similar conclusion ${ }^{21}$ for $\mathrm{Cu}$ suggests that GGA studies of $\mathrm{Pb}$ wetting of $\mathrm{Cu}$, i.e., in solder joint formation, are likely to produce information of value. 


\section{S-ENHANCED RIPENING OF Cu ISLANDS ON Cu(111)}

Confirming the interpretation of data from well-characterized surfaces is only one way that theory may help in STM studies related to collective diffusive behaviors. In this section I review an example of another ${ }^{11}$ - uncovering the mechanism by which surface impurities modify the time evolution of a surface morphology.

The problem is to understand why monolayer-high $\mathrm{Cu}$ islands on thick $\mathrm{Cu}(111)$ films ripen $\sim 3-4$ orders of magnitude faster when $\mathrm{S}$ is adsorbed than when the surface is clean. ${ }^{10}$ To solve it, one must first decide what process is rate-limiting in the clean situation, then learn how $\mathrm{S}$ accelerates it.

There are two general possibilities. The first is that the $\mathrm{Cu}$ current across a (111) terrace is dominated by the barriers that impede dissociation from, and attachment to kinks. The other is that ripening is "diffusion limited," or in other words, that transport across terraces by the quasi-equilibrium sea of $\mathrm{Cu}$ adspecies is rate-limiting. ${ }^{22}$

In principle, the power law that describes the time-dependence of island ripening reveals which possibility is operative. However, in the present case, ripening happens very slowly when no $S$ is present and very quickly once $S$ is deposited. 'Accordingly there is insufficient data as yet to permit experimental determination of the rate-limiting barriers.

In the absence of experimental information, I argue on geometric grounds that the barrier to split an adatom off a kink on a $\mathrm{Cu}$ island should be close to the sum of the adatom formation energy and the adatom diffusion barrier. This is the same energy that controls the diffusion current on a terrace, which suggests focusing exclusively on this energy sum.

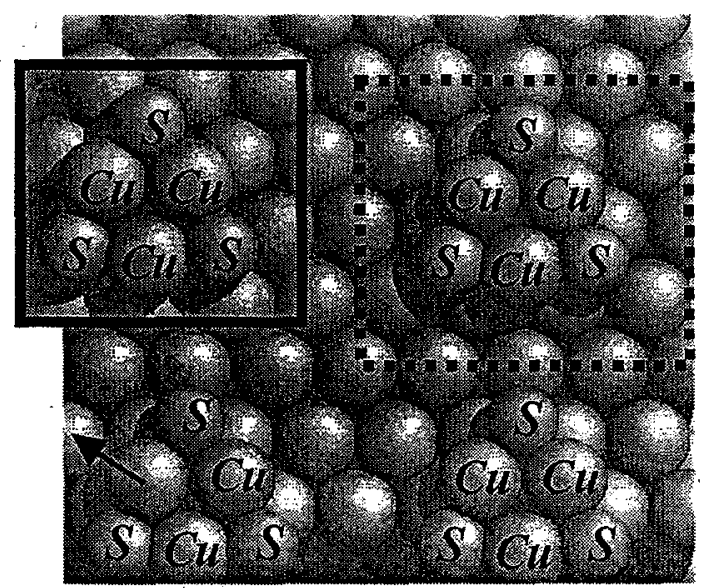

Fig. 2. $\mathrm{Cu}_{3} \mathrm{~S}_{3}$ ad-clusters on $\mathrm{Cu}(111)$, in the $4 \times 2 \sqrt{3}$ supercell indicated by the dotted rectangle. The inset cluster is displaced by the distance between $f c c$ and $h c p$ hollows, in the direction indicated by the arrow. As a result, the S-atoms that cover it are on (111)-microfacets, rather than the (100)-microfacets of the undisplaced clusters. This change of $\mathrm{S}$-adsorption geometry is the main source of the $0.35 \mathrm{eV} \mathrm{Cu}_{3} \mathrm{~S}_{3}$ diffusion barrier. 
The big contribution to this sum is the energy needed to form a $\mathrm{Cu}$ adatom or a cluster of them. The reason is that closer-packing means better coordinated first-layer atoms, and therefore that self-adsorption is maximally costly on close-packed surfaces. The GGA implies, e.g., that $0.79 \mathrm{eV}$ is needed to form a $\mathrm{Cu}$ adatom on $\mathrm{Cu}(111)$. This means that at $300 \mathrm{~K}(=26 \mathrm{meV})$, the equilibrium concentration of self-adsorbed $\mathrm{Cu}$ atoms is low and might be significantly larger when $\mathrm{S}$ adatoms are added to the surface. (See Ref. 11 , for details of the ab-initio calculations.)

The same logic that predicts a big adatom formation energy suggests that the selfdiffusion barrier on clean $\mathrm{Cu}(111), \mathrm{E}_{\text {diff }}(\mathrm{ad}-\mathrm{Cu})$, should be small. Again the GGA agrees, predicting $E_{\text {diff }}(\operatorname{ad}-\mathrm{Cu}) \approx 57 \mathrm{meV}$. Since this energy is small with no $S$ on the surface, only a small contribution to island ripening speed can come from reducing it further by depositing $\mathrm{S}$.

Accordingly, I postulate that $\mathrm{S}$ impurities promote island-ripening by forming tightly-bound, and thus plentiful and mobile $\mathrm{Cu}_{\mathrm{n}} \mathrm{S}_{\mathrm{m}}$ ad-species, ${ }^{23}$ and, via ab-initio totalenergy calculations, I systematically search for those that are favored compared to an unadorned $\mathrm{Cu}$ adatom. The search points to $\mathrm{ad}_{-} \mathrm{Cu}_{3} \mathrm{~S}_{3}$ (See Fig. 2) as the best candidate.

\section{Comparison of cluster formation energies}

The abundance of ad- $\mathrm{Cu}_{\mathrm{n}} \mathrm{S}_{\mathrm{m}}$ is determined by its chemical potential. It equals the chemical potential of ad- $\mathrm{Cu}_{\mathrm{n}}$ less that gained by $m$ ad-S's attaching to form a decorated cluster. I compute this gain by reference to the isolated ad-S chemical potential, $\mu$ (ad$S)=E_{B}(a d-S)-k_{B} T \ln \theta_{S}$, where $E_{B}($ ad-S $)$ is the ad-S binding energy and $k_{B} T \ln \theta_{S}$ accounts for the entropy loss per $S$, at ad-S concentration $\theta_{S}$. Entropy-loss drives up the free energy cost of clusters according to the number of $S$ atoms they abstract from the terrace lattice-gas. This inhibits formation of clusters containing many $\mathrm{S}$ adatoms.

\section{Cu adatoms}

Values of $E_{\text {form }}(\mathrm{ad}-\mathrm{Cu})$ and $\mathrm{E}_{\mathrm{diff}}(\mathrm{ad}-\mathrm{Cu})$ are derived from total energies of adatomcontaining supercells large enough that inter-adatom interactions are small. I find that $\mathrm{Cu}$ adatoms prefer $f c c$ to $h c p 3$-fold sites on the 6-layer slab by only $7 \mathrm{meV}$. Correspondingly, the ad-Cu diffusion barrier lies almost equidistant from the 3-fold hollows at a twofold bridge. To an excellent approximation, $E_{\text {diff }}(\mathrm{ad}-\mathrm{Cu})$ is thus the difference in energies for an ad- $\mathrm{Cu}$ in an $f c c$ hollow and at the symmetric bridge. The computed sum, $E_{\text {form }}(\mathrm{ad}-\mathrm{Cu})+\mathrm{E}_{\mathrm{diff}}(\mathrm{ad}-\mathrm{Cu})=0.85 \mathrm{eV}$, compares well with the value, $0.78 \pm 0.04 \mathrm{eV}$, obtained from STM observations of $\mathrm{Cu}$ island decay on clean $\mathrm{Cu}(111)^{4}$ Effective Medium Theory calculations by Stoltze yield $0.71 \mathrm{eV}$ and $53 \mathrm{meV}$ for $\mathrm{E}_{\text {form }}(\mathrm{ad}-\mathrm{Cu}$ ) and $E_{\text {diff }}(a d-C u),{ }^{24}$ in relatively good agreement with the best ab-initio results, $0.79 \mathrm{eV}$ and $57 \mathrm{meV}$. (Calculated resultš are summarized in Table I.) 
Table I: Cluster formation energies, $E_{\text {form, }}$ on a 6-layer, $\mathrm{Cu}(111)$ slab. $\mathrm{N}_{\mathrm{S}}$ and $\mathrm{N}_{\mathrm{Cu}}$ are the numbers of $\mathrm{S}$ and $\mathrm{Cu}$ adatoms in each cluster. For $\mathrm{Cu}$ dimers and trimers I indicate the face that the $\mathrm{S}$ atoms decorate. The " $\mathrm{B}$ " cases correspond to $\mathrm{Cu}$ 's in hop hollows. In all other cases the Cu's occupy foc sites. For the Cu monomer plus one $\mathrm{S}$ adatom, the three $E_{\text {form }}$ values are for $S$ down, $\mathrm{Cu}$ down and $\mathrm{S}$-beside-Cu configurations

\begin{tabular}{|c|c|c|c|}
\hline$N_{S}$ & $N_{C u}$ & face & $E_{f o r m}(e V)$ \\
\hline 0 & 1 & & 0.79 \\
\hline 1 & 1 & & $1.26,1.87,1.87$ \\
\hline 0 & 2 & & 1.33 \\
\hline 1 & 2 & A & 1.29 \\
\hline 2 & 2 & & 1.06 \\
\hline 0 & 3 & A & 1.69 \\
\hline 3 & 3 & A & 0.28 \\
\hline 3 & 3 & B & 0.62 \\
\hline 4 & 4 & & 0.49 \\
\hline 5 & 4 & & 1.09 \\
\hline
\end{tabular}

\section{Cu-S ad-dimers}

If ad-CuS is the plentiful species that accounts for S-enhanced $\mathrm{Cu}$ transport, ${ }^{11}$ at a minimum ad-Cu and ad-S must attract. But they do not. A S adatom loses $1.08 \mathrm{eV}$ binding energy in approaching an ad-Cu closely. Thus, forming a $\mathrm{Cu}-\mathrm{S}$ dimer with the $\mathrm{S}$ beside the $\mathrm{Cu}$ costs $1.87 \mathrm{eV}^{25}$ Presumably because the $\mathrm{S}$ cannot conveniently form two bonds, repulsion of the same magnitude also blocks formation of an ad-CuS with the $\mathrm{Cu}$ end down. On the other hand, even with the S-end down, allowing $\mathrm{S}$ and $\mathrm{Cu}$ valence requirements to be satisfied, the dimer formation energy (with the $\mathrm{CuS}$ in an fcc hollow) is $1.26 \mathrm{eV}$, compared to $\mathrm{E}_{\text {form }}(\mathrm{ad}-\mathrm{Cu})=0.79 \mathrm{eV}$. The $\mathrm{Cu}-\mathrm{S}$ adcluster responsible for enhanced $\mathrm{Cu}$-island decay thus contains more than one $\mathrm{Cu}$ atom.

\section{Clean and S-decorated Cu dimers}

One expects $\mathrm{Cu}$ 's adsorbed on $\mathrm{Cu}(111)$ to attract, and indeed $\mathrm{Cu}-\mathrm{Cu}$ attraction lowers $E_{\text {form }}\left(\mathrm{ad}-\mathrm{Cu}_{2}\right)$ by $0.27 \mathrm{eV}$. But does attaching $\mathrm{S}$ atoms to such a dimer reduce its $\mathrm{E}_{\text {form }}$ by another $0.53 \mathrm{eV}$, to make S-decorated $\mathrm{Cu}$-dimers more plentiful than $\mathrm{Cu}$ monomers? At least for the most obvious S-decorations of $\mathrm{Cu}$ addimers, the answer is no. Placing a single $\mathrm{S}$ on the side of the dimer, where it is 4-coordinated, lowers the formation energy by $0.04 \mathrm{eV}$. Adding another, on the other side of the dimer lowers it $0.19 \mathrm{eV}$ 
more, not enough to compensate the cost of the second ad-Cu. Other geometries, e.g., Cu's decorating a S-addimer, or S's and Cu's alternating to form a flat tetramer, seem unfavorable. The former requires $S$ 's to be nearest neighbors even while $S_{2}$ dissociates on $\mathrm{Cu}(111)$. The latter is unlikely because an ad-S repels an adjacent ad-Cu.

\section{Clean and S-decorated Cu trimers.}

Per adatom, forming $\mathrm{Cu}$ ad-trimers should cost less than dimers, because each ad$\mathrm{Cu}$ has two ad-Cu neighbors, not one. Counting bonds, with a $\mathrm{Cu}-\mathrm{Cu}$ bond strength of $0.27 \mathrm{eV}$ (see above), one expects $\mathrm{E}_{\text {form }}\left(\mathrm{ad}_{-} \mathrm{Cu}_{3}\right) \approx 1.59 \mathrm{eV}$, i.e., about triple the monomer formation energy, $2.4 \mathrm{eV}$, minus $3 \times 0.27 \mathrm{eV}$.

Direct calculations confirm this logic. The energy needed to form a trimer (see Fig. 2 ), with the three $\mathrm{Cu}$ adatoms in neighboring fcc hollows bounded by (100)- or "A-type" microfacets, is $\sim 1.7 \mathrm{eV}$. If the trimer is rotated $60^{\circ}$, so that its sides are (111)- or "B-type" microfacets, its $E_{\text {form }}$ is $0.02 \mathrm{meV}$ less. ${ }^{26}$

Though bond-counting predicts $\mathrm{E}_{\mathrm{form}}\left(\mathrm{ad}-\mathrm{Cu}_{3}\right)$ rather well, a similar approach greatly underestimates how much S-decoration reduces it. Rather than by 0.1 to $0.2 \mathrm{eV}$ per added $\mathrm{S}$-atom, as $\mathrm{S}+\mathrm{Cu}$-dimer results would suggest, decorating a $\mathrm{Cu}$ trimer with three $\mathrm{S}$ atoms reduces the formation energy of the complex by $0.47 \mathrm{eV} / \mathrm{S}$-atom, for a trimer bounded by A-type microfacets. Forming S-decorated Cu trimers thus costs only $0.28 \mathrm{eV}$, much less than $\mathrm{Cu}$ monomers!

\section{Diffusion of S-decorated Cu trimers}

Given that creating a $\mathrm{Cu}_{3} \mathrm{~S}_{3}$ ad-complex costs just $0.28 \mathrm{eV}$, and the related fact that S-decoration lifts the $\mathrm{Cu}$ adatoms $\sim 0.14 \mathrm{~A}$ higher above the nearest surface $\mathrm{Cu}$ 's, the cluster diffusion barrier should be low. A plausible diffusion path involves moving each $\mathrm{Cu}$ from its initial hollow, say an $f c c$ site, ${ }^{27}$ (along the arrow in Fig. 3) over a neighboring bridge to an adjacent $h c p$ hollow, the three $\mathrm{S}$ atoms following more or less rigidly. A lower bound for the barrier along this path is the energy difference between the initial and final configurations of the decorated trimer, or (see Fig. 2) between S-decorated trimers with A- vs. B-type sides.

This bound is significant, because $\mathrm{S}$ atoms have an affinity for $\mathrm{Cu}$ 's arranged in a square. ${ }^{28}$ In the present case, the affinity amounts to an energetic preference of $\sim 0.33 \mathrm{eV}$ for an A-sided trimer. It remains to learn if the B-trimer represents a transition geometry or a metastable state, and if the latter, whether the minimum barrier is much bigger than $0.33 \mathrm{eV}$.

Applying Jónsson's Nudged Elastic Band (NEB) method ${ }^{29}$ with two replicas of the S-decorated trimer along the path between A-trimer in $f c c$-and B-trimer in $h c p$-hollows, I find a transition state close to the B-trimer geometry and a barrier of $0.35 \mathrm{eV}$. Thus $E_{\text {form }}\left(\mathrm{Cu}_{3} \mathrm{~S}_{3}\right)+\mathrm{E}_{\text {diff }}\left(\mathrm{Cu}_{3} \mathrm{~S}_{3}\right) \approx 0.63 \mathrm{eV}$, which is $0.22 \mathrm{eV}$ lower than the similar sum for a $\mathrm{Cu}$ adatom. 
Assuming "diffusion-limited" Cu-island ripening, ${ }^{22}$ the decay-rate scales with the concentration of $\mathrm{Cu}$-carrying adspecies times their diffusion constant. This product is proportional to $D_{0}(\mathrm{ad}-\mathrm{Cu}) \exp \left\{-\left[\mathrm{E}_{\text {form }}(\mathrm{ad}-\mathrm{Cu})+\mathrm{E}_{\mathrm{diff}}(\mathrm{ad}-\mathrm{Cu})\right] / \mathrm{k}_{\mathrm{B}} \mathrm{T}\right\}$, for $\mathrm{Cu}$-adatom transport, and to $\mathrm{D}_{0}\left(\mathrm{Cu}_{3} \mathrm{~S}_{3}\right) \theta_{\mathrm{S}}{ }^{3} \exp \left\{-\left[\mathrm{E}_{\text {form }}\left(\mathrm{Cu}_{3} \mathrm{~S}_{3}\right)+\mathrm{E}_{\mathrm{diff}}\left(\mathrm{Cu}_{3} \mathrm{~S}_{3}\right)\right] / \mathrm{k}_{\mathrm{B}} \mathrm{T}\right\}$, for $\mathrm{Cu}_{3} \mathrm{~S}_{3}$ clusters, where the $\mathrm{D}_{0}$ 's are diffusion prefactors. ${ }^{30}$ The $\mathrm{S}$-induced speedup is proportional to three times the latter divided by the former. ${ }^{31}$ So the predicted $\mathrm{Cu}_{3} \mathrm{~S}_{3}$-mediated decay rate $\approx 15000 \theta_{\mathrm{S}}{ }^{3} \times \mathrm{D}_{0}\left(\mathrm{Cu}_{3} \mathrm{~S}_{3}\right) / \mathrm{D}_{0}$ (ad-Cu) that for clean $\mathrm{Cu}(111)$. This result makes it plausible that $\mathrm{Cu}_{3} \mathrm{~S}_{3}$ clusters account for the speedup seen in Ref. 2 . Whether they really do depends largely on the $D_{0}$ 's.

\section{Clean and S-decorated $\mathrm{Cu}$ tetramers}

The advantages of additional $\mathrm{Cu}-\mathrm{Cu}$ bonds and $\mathrm{S}$-decoration persist beyond $\mathrm{Cu}$-trimers. To form ad- $\mathrm{Cu}_{4} \mathrm{~S}_{4}$, e.g., requires only $\sim 0.49 \mathrm{eV}^{32}$ However, since barriers to concerted diffusion of $\mathrm{Cu}_{\mathrm{n}} \mathrm{S}_{\mathrm{n}}$ clusters likely rise with $n$, and concentration of clusters containing $p \mathrm{~S}$-atoms is reduced by $\theta_{\mathrm{S}}^{p}$ by entropy loss (cf. Ref. 32). Cu-transport via Sdecorated tetramers, pentamers, etc. should be less important than via $\mathrm{Cu}_{3} \mathrm{~S}_{3}$

\section{Observation of $\mathrm{Cu}-\mathrm{S}$ ad-clusters}

Quench experiments that directly reveal $\mathrm{Cu}_{3} \mathrm{~S}_{3}$ on terraces would obviously be desirable. A suggestive result in this direction is that STM of a low-T "honeycomb phase" of $\mathrm{S} / \mathrm{Cu}(111)$, exhibits one surface protrusion per deposited $\mathrm{S}$, separated by $\sim 4 \AA{ }^{33}$ I find an S-S separation of $4.4 \AA$ for ad- $-\mathrm{Cl}_{3} \mathrm{~S}_{3}$.

\section{CONCLUSION}

Because $a b$-initio methods can now confidently be applied to problems involving rather complicated surface morphologies and virtually any elemental composition, we can and should check assumptions made in the course of STM data analysis with reliable, parameter-free calculations. Moreover, we can and should try to fill in key mechanistic details that underlie the observed time-evolution of STM images. In short, $a b$ initio total energy calculations should now be viewed as an indispensable tool for the analy sis of scanning probe data.

\section{ACKNOWLEDGEMENTS}

I thank N. C. Bartelt and B. S. Swartzentruber for many helpful discussions. This work was supported by the U. S. Department of Energy under Contract No. DE-AC0494AL 85000 . Sandia is a multi-program laboratory operated by Sandia Corporation, a Lockheed Martin Company, for the U. S. Department of Energy. 


\section{REFERENCES}

1. P. J. Feibelman, Surf. Sci. Lett. (in press).

2. P. J. Feibelman, Phys. Rev. B (submitted).

3. M. Giesen, G. S. Icking-Konert, D: Stapel and H. Ibach, Surf. Sci. 366, 229 (1996).

4. G S. Icking-Konert, M. Giesen and H. Ibach, Surf. Sci. 398, 37(1998), Phys. Rev. Lett. 83, 3880(1999)

5. D. C. Schlößer, L. K. Verheij, G. Rosenfeld and G. Comsa, Phys. Rev. Lett. 82, 3843(1999).

6. K. Arenhold, S. Surnev. H. P. Bonzel and P. Wynblatt, Surf. Sci. 424, 271(1999); ibid., 441, 223(1999).

7.. H-C. Jeong and E. D. Williams, Surf. Sci. Rep. 34, 171(1999).

8. For an impressive bibliography, see W. F. Egelhoff, et al., J. App. Phys. 79, 2491(1996)

9. E.g., P. J. Feibelman, Phys. Rev. Lett. 81, 168(1998) and M. Kalff, G Comsa, T. Michely, ibid. 81, 1255 (1998).

10. K. Pohl, et al., unpublished.

11. P. J. Feibelman, Phys. Rev. Lett. 85, 606(2000).

12. R. Stumpf, Phys. Rev. B53, R4253 (1996); S. Horch, et al., NATURE 398, 134(1999).

13. Th. Michely and G. Comsa, Surf. Sci. 256, 217(1991).

14. M. Giesen, C. Steiner and $H$. Ibach, preprint.

15. B. S. Swartzentruber, Y.-W. Mo, R. Kariotis, M. G. Lagally, and M. B. Webb, Phys. Rev. Lett. 65, 1913(1990).

16. P. Hohenberg and W. Kohn, Phys. Rev. 136, B864 (1964); W. Kohn and L. J. Sham, Phys. Rev. 140, A1133 (1965).

17. G. Boisvert, L. J. Lewis and M. Scheffler, Phys. Rev. B57, 1881(1998).

18. M. Giesen and $\mathrm{H}$. Ibach, private communication.

19. N. Akutsu and Y. Akutsu, J. Phys. Cond. Mat. 11, 6635(1999), Eq. 4.33 for step stiffness and Eq. 4.31 for step free energy. Limiting their applicability to the $\mathrm{Pb}(111)$ surface, somewhat, results in this article are derived for a six-fold symmetric hexagonal Ising model wherein A- and B-step energies are equal and comer energies vanish.

20. J. P. Perdew, in Electronic Structure of Solids ' 91 , edited by P. Ziesche and H. Eschrig (Akademie Verlag, Berlin, 1991); J. P. Perdew and Y. Wang, unpublished.

21. P. J. Feibelman, Phys. Rev. B60, 11118 (1999).

22. J. G. McLean, et al., Phys. Rev. B55, 1811(1977).

23. Ad- $\mathrm{Cu}_{n} \mathrm{~S}_{\mathrm{m}}$ may also underlie the $\mathrm{S} / \mathrm{Cu}(111)$ phases reported by $E$. Wahlström, et al., Phys. Rev. B60, 10699(1999).

24. P. Stoltze, J. Phys. Cond. Mat. 6, 9495(1994).

25. This is not an unusual effect. For the case of $\mathrm{Al}$ and $\mathrm{S}$ on Al(100), see P. J. Feibelman, Phys. Rev. B38, 12133 (1988).

26. Consistent with a lower B- than A-step formation energy, as in Ref. 21.

27. Starting the A-trimer with Cu's in hop hollows should make little difference.

28. M. Foss, et al., Surf. Sci. 388, 5(1997).

29. H. Jönsson, G. Mills, K. W. Jacobsen, in Classical and Quantum Dynamics in Condensed Phase Simula. tions, ed. B. J. Berne, G Ciccotti and D. F. Coker (World Scientific, 1998).

30. $\theta_{\mathrm{S}}{ }^{3}$ represents entropy loss when three lattice-gas $S$ adatoms attach to a trimer.

31. The factor 3 accounts for the three $\mathrm{Cu}$ atoms that each trimer contains.

32. The $\mathrm{Cu}$ 's of the ad- $\mathrm{Cu}_{4} \mathrm{~S}_{4}$ form a parallelogram with two Cu's roughly in 3-fold hollows and two in bridgesites. A fifth $\mathrm{S}$ atop ad- $\mathrm{Cu}_{4} \mathrm{~S}_{4}$ is unhelpful, with $\mathrm{E}_{\text {form }}\left(\mathrm{ad}-\mathrm{Cu}_{4} \mathrm{~S}_{5}\right) \approx 1.09 \mathrm{eV}$.

33. E. Wahiström, et al, op. cit. 